\title{
BELAJAR DENGAN SANG SINGA
}

\author{
Oleh Drs. Moh. Waslah, M.Pd.I. *
}

\begin{abstract}
Abstrak
Judul tulisan ini disengaja dengan maksud untuk mencakup ragam kebutuhan dan obyek belajar. Satu sisi bisa berarti belajar kepada hewan singa, atau belajar kepada obyek sumber yang mendapatkan label masyarakat dengan singa disebabkan karena memilliki sifat-sifat keperkasaaan layaknya singa dan bisa juga belajar kepada sebuah sistem yang dimiliki oleh negeri yang menggunakan simbol singa. Tulisan ini dimasudkan untuk memberikan wawasan pengertian kepada kita untuk mengambil pelajaran dalam meningkatkan peran yang kita sandang dalam keseharian.
\end{abstract}

Kata Kunci : Singa, belajar.

\section{Pendahuluan}

Belajar adalah usaha untuk mencapai suatu kepandaian (Poerwadarminta,1986 : 108). Belajar dapat dilakukan melalui orang lain baik guru, pembimbing, fasilitator ataupun siapa saja yang memiliki kepandaian dan dapat berfungsi sebagai sumber belajar. Orang tua di rumah dalam pengertian ini sebenarnya adalah guru dan tempat sumber belajar anak. Belajar tentu banyak ragamnya sangat tergantung pada sisi apa yang menjadi tujuan. Belajar pemahaman dilakukan dengan memahami sesuatu. Belajar ketrampilan dilakukan dengan pemahaman dan pelatihan. Belajar untuk merasakan dilakukan dengan pelatihan diri sehingga mampu merasakan. Hal ini sering disebut dengan penghayatan. Sisi yang dipertajam dengan belajar pun banyak meliputi nalar (rasio), rasa atau perasaan, ketrampilan dan kecekatan.

* Dosen PAI Fakultas Agama Islam UNWAHA TAMBAKBERAS JOMBANG 


\section{Moh. Waslah}

\section{Belajar dengan hewan Singa}

Sebuah pepatah menyatakan "Sebuas-buas singa tidak akan memangsa anaknya" agaknya menjadi ungkapan yang bermakna . Singa adalah binatang yang menakutkan, tubuhnya besar, gesit dan garang, buas dan menyeramkan. Singa memiliki taring yang gampang melumatkan mangsanya, punya kuku yang kuat yang mampu menerkam mangsa hingga tak berdaya, dan mencabikcabiknya. Singa sering digunakan untuk mewakili kekuatan, kegarangan dan kebuasan. Meskipun buas dan garang singa ternyata dapat dididik. Perhatikan kebanyakan sirkus-sirkus dunia pasti menampilkan pula hewan ini dalam atraksinya. Jika seorang pawang telah memberinya perintah maka layaknya anak didik singa-singa itu akan melakukan apa yang diperintahkan sang pelatih .

Namun singa sebagai hewan garang dan buas, secara naluriah tidak mungkin menggunakan kekasaran kepada anak-anaknya, bahkan dia sangat lembut. Singa betina mengelus-elus anaknya yang masih kecil dengan lidah dan bagian kepalanya. Singa jantan mengawasi dan mengawal betina dan anakanaknya dari gangguan binatang buas lainnya.

Gambaran itulah yang kita lihat dalam Serial Televisi Wild Animal dan juga kita saksikan ketika kita berkunjung ke kebun binatang. Jadi ternyata kebuasan singa hanya dilakukan ketika menghadapi ancaman pada dirinya dan diketika mengasuh anak-anak singa tetap melakukan dengan lemah lembut. Bahkan meskipun singa itu lapar dan harus makan tidak akan dan tidak mungkin 
memangsa anaknya sendiri. Dia akan mencari makanan secara bergantian antar pejantan dan pasangannya dan setelah mendapatkannya dbawa pulang untuk dimakan bersama anak-anaknya.

\section{Belajar Umar bin Khaththab Sang Singa Padang Pasir}

Umar bin Khaththab r.a (581-644 M) adalah orang penting dalam perjalanan dakwah Rasulullaah SAW. Beliau menjadi Khalifah ke dua menggantikan Abu Bakar Ash-Shiddiq dan memerintah selama 10 tahun (634-644 M) Beliau terkenal sebagai pemimpin yang takwa, tegas dan adil dalam membela kebenaran. Masuk Islam pada 4 tahun sebelum Hijrah (Shadily; 6 : 3701). Dalam masa mudanya sangat di takuti oleh musuhnya karena keperkasaannya dan ketangkasannya sehingga orang menyebutnya sebagai Singa Padang Pasir. Rasulullah memberi julukan Al-Faruuq yang sepadan maknanya dengan AlHakim artinya Yang Arif bijaksana (Bisri ,1999 : 566). Beliau setelah mendapatkan hidayah Islam berubah sifatnya dari perilaku garang, menakutkan ibarat singa menjadi pribadi yang sangat arif dan bijaksana.

Suatu sore seorang pegawai Umar bin Khaththab memerlukan datang ke rumah Umar bin Khaththab karena ada sesuatu yang harus dilaporkan. Tentu saja ia sangat hati -hati ketika mengetuk pintu dan mengucapkan salam tidak lain karena kewibawaan Khalifah Umar. Umar masih dikesankan sebagaimana di zaman mudanya yang pemberani yang membuat gemetar lawan atau musuhnya. 


\section{Moh. Waslah}

Kekekaran dan kegarangan mewakili tampilannya.Rupanya ketukan pertama tidak segera mendapatkan jawaban dengan dibukanya pintu oleh tuan rumah. Pegawai itu mendengar di dalam rumah itu sedikit ramai oleh cengkerama anakanak yang kedengaran sedang asyik dalam permainan, derai tawa anak dan orang dewasa bercampur terdengar jelas dari luar. Pegawai itu mengulangi ketokan pintunya lagi dengan lebih keras. Maka serta merta ketika tuan rumah membukakan pintu, kagetlah pegawai tadi menyaksikan bahwa atasannya Sang Khalifah Umar bin Khaththab sedang bercengkerama dengan anaka- anak beliau . Beliau menjadi kuda dan dinaiki oleh anak -anaknya dan memukul-mukulnya. Keterkejutan itu dilahirkan dengan menyatakan 'Engkaulah wahai amirul mukminin sedemikian dekat dan melakukan permainan dengan anak-anak dalam keseharian?'. Umar menjawab : 'Ya beginilah saya dengan anak-anak dan cucu saya'. Dalam fikiran pegawai tadi kewibawaan, keperkasaan dan kekasaran kekuatan Umar di luar rumah berubah dan tidak berlaku di dalam rumah. 'Apakah engkau tidak melakukannya terhadap anak-anak dirumahku?' tanya Umar kepada pegawainya itu. 'Tidak wahai Umar, anak anakku sangat takut kepadaku" Jawab pegawai tadi. 'Jika demikian engkau akan kehilangan nikmatnya berkeluarga" tandas Khalifah Umar bin Khaththab.

Memang dalam masyarakat ada sebahagian orang tua yang bangga bila ditakuti istri dan anak -anak di rumah. Meski sebagai pegawai rendahan tetapi berlagak pembesar yang sewot dengan banyak urusan. Sebagai ayah berusaha 
seperti raja yang perkataannya harus dituruti dan tidak boleh dibantah. Perbuatannya selalu menyalahkan seisi rumah tidak menaruh kepercayaan sedikitpun.

Di media televisi pun kita disuguhi tontonan orang tua yang marah-marah, menghardik sana, membanting barang di hadapan anak istri. Seolah ingin membuat alur anti klimaks yang ekstrim. Demikian membuat adegan konflik antara orang tua dan anaknya yang kelewat kasar, dengan berdalih mewakili masyarakat yang sudah senang berbuat kasar. Mungkin hanya Pak Haji dalam serial film Kiamat Sudah Dekat yakni ayahnya Sarah saja yang menampilkan contoh bermutu. Ia sangat memahami perasaan anaknya, ia bisa dekat dengan anak kecil yang tidak punya yakni Kipli dan Safrol. Orang tua tidak dekat dan menyayangi anak tentu tidak akan merasakan nikmatnya berkeluarga.

\section{Belajar pada falsafah Atraksi Sisingaan}

Di daerah Singaparna pada khususnya dan Jawa Barat pada umumnya anak yang menginjak dewasa yang ditandai dengan dikhitan. Pada upacara khitan tersebut dilakukan atraksi masyarakat yang di namakan sisingaan. Yakni anak yang dikhitan diarak keliling kampung dengan menaiki singa buatan, yang berupa patung singa yang ditempatkan di atas papan dengan dipikul oleh empat orang pemuda. Atraksi itu menarik karena anak yang menginjak dewasa 


\section{Moh. Waslah}

dinaikkan ke patung buatan yang menggambarkan hewan yang seram yang biasanya ditakuti. Mengapa bukan kuda, lembu atau kambing.?

Apabila dilihat dari kacamata awam permainan itu disamping sebagai atraksi namun tidak lepas dari nilai pendidikan yang ingin di tanamkan. Khitan adalah simbol awal memasuki usia dewasa. Anak ketika menginjak dewasa diajari untuk tidak perlu merasa takut pada hewan ganas dan justru harus ditaklukkan dengan menjadikannya sebagai tunggangan. Jadi atraksi ini ingin mendidik bahwa seorang yang dewasa harus mampu menandingi kebuasan hewan singa yang menjadi rajanya rimba raya. Persiapan itu harus dilakukan karena mereka (anak-anak) itu nanti akan dewasa dan hidup mandiri.

\section{Belajar ke Singapura?}

Kita punya tetangga negara yang separuh jaraknya dibanding jarak Jakarta Medan atau ke Aceh. Negeri kecil yang luasnya dapat ditandingi oleh luas pulau Tri Pulau Barelang (Batam, Rempang dan Galang) yang telah dihubungkan dengan jembatan antar pulau. Luas wilayahnya $621,4 \mathrm{~km}^{2}$. Penduduk sekitar 3 juta jiwa. Negara yang semua keperluan pokok rakyatnya diimport dari luar, tetapi memiliki fungsi strategis dalam perdagangan dunia karena diuntungkan oleh lokasinya sebagai pintu lalu lintas dunia. Sebenarnya kita memiliki pulau yang dekat seperti Batam, Bintan dll yang sedang diupayakan untuk Bourden Cirkle atau lingkungan penyangga. Karena sulit untuk mengalihkan ketenaran 


\section{Belajar Dengan Sang Singa}

kota tersebut karena sarana, fasilitas dan sistem yang dimilikinya sudah jauh lebihmaju dibandingkan yang dapat disipkan oleh Indonesia.

Singapura memiliki simbul singa ternyata berperan besar dalam lalu lintas perdagangan dunia. Pelabuhan kargonya sangat sibuk. Negeri Singapura berbentuk Republik ini dipimpin seorang Perdana Menteri yakni Goh Coh Tong. Pergantian kepemimpinan dari PM sebelumnya yakni Lee Kuan Yu melalui penunjukan dan baru disyahkan oleh Parlemen. Termasuk negeri yang sangat diminati untuk pelancongan, berobat, ngumpet, pencucian uang haram dan tempat pendidikan. Untuk pendidikan berulang kali iklan muncul di Televisi kita dengan memperkenalkan The Cool Campus. Setelah masa krisis di Indonesia banyak pengusaha yang lari dan bersembunyi di negeri ini. Dan setelah Presiden Susilo Bambang Yudoyono melacak uang yang berasal dari perbuatan korupsi banyak pelaku yang melarikan diri dan bersembunyi di sana sulit disentuh oleh deteksi aparat. Tak ayal Jaksa Basri Arif yang memburu harta koruptor harus membuat agreement dengan negara tersebut untuk mendapat tahu di maana dana itu disembunyikan.

Kemajuan yang dicapai Singapura tentu dari kerja keras para pengelola negara dengan rakyat. Dan yang harus menjadi catatan meski Negara kecil tetapi Indonesia tidakkan berani mengganggu karena tentu takut akan kebuasannya. 


\section{Moh. Waslah}

\section{Mari kita Belajar dari Singa.}

Negara yang mau maju dan berharkat harus mendidik masyarakat untuk meningkatkan wawasan dan ilmunya. Islam memberi keleluasaan kepada pemeluknya untuk belajar kepada siapa saja, berimankah dia atau tidak beriman bahkan kepada orang kafir pun tidak dilarang. Manakala kita merenung kepada tradisi sisingaan yang berkait dengan pesan kepada anak untuk tidak takut kepada binatang buas dan belajar kepada Negeri Singa adalah untuk mempelajari ketertiban, keteraturan, kesungguhan dalam membangun negeri yang minim SDA menjadi negeri yang berjaya. Maka belajar pepatah dan belajar kepada Sang Singa Padang pasir yakni Umar bin Khaththab adalah dalam rangka mengasah hati nurani agar menjadi manusia yang menjaga amanah dan bertanggung jawab terhadap anak dan keturunan yang diamanahkan oleh Allah kepadanya. Orang tua mempunyai kewajiban mendidik anak yang lahir dari rahim istri yang dinikahinya jika ia seorang bapak atau dari rahimnya jika seorang ibu.

Mendidik mestilah dengan sabar dan kasih sayang. Anak-anak kita adalah penerus kita dan mereka akan menjadi penopang, sekaligus menaburkan kebahagiaan abadi bagi orang tuanya meskipun telah di alam baka. Doa orang tua bagi anak dan doa anak kepada orang tua sebegitu dekat hampir tanpa batas sehingga menjadi tumpuan harapan kebahagiaan bagi orang tua yang berhasil menanamkan pendidikan kepada anaknya dengan sabar dan kasihsayang. Allah 


\section{Belajar Dengan Sang Singa}

memerintahkan orang tua mendidik anak dengan baik dan besabar. Firman Allah dalam Al-Qur'an :

Artinya : 'Dan didiklah kelurgamu mendirikan shalat dan bersabarlah kamu dalam mengerjakannya. Kami akan meberi rizki kepadamu. Dan akibat dari perbuatan yang baik itu hanya bagi orang yang bertakwa' QS. Thaha:132

Perilaku anak adalah berada dalam dunia anak itu sendiri dan berada ketidak tahuannya. Menurut para pakar pendidikan tidak ada anak yang nakal. Sebab banyak orang tua menganggap anak yang melakukan sesuatu perbuatan tertentu- yang terkadang membahayakan dirinya sendiri - sebagai perbuatan nakal. Padahal perbuatan itu dilakukan anak karena anak terdorong rasa ingin tahu terhadap sesuatu, sedangkan ia belum tahu bagaimana mengambilnya dengan cara aman. Atau anak itu belum dapat mempertimbangkan resiko suatu perbuatan yang dilakukan. Dengan kata lain anak belum dapat melakukan pertimbangan dengan baik seperti halnya orang dewasa. Dengan demikian justru orang tua yang harus mendekati anak seakan-akan pikiran mereka itu lengkap, utuh dan berfungsi. Orang tua sudah semestinya memberikan pemahaman kepada anak sesuai dengan alam pikiran dan bahasa mereka. Erich Jantsch menyatakan bahwa pemahaman bukanlah pengetahuan yang statis, melainkan proses evolusi itu sendiri (Bob Samples,2002 : 138).

Orang tua dan siapapun yang menjadi wali anak itu wajib memberi bimbingan agar mereka mengerti dan melakukan sesuatu yang benar. Kekasaran dan kebencian terhadap anak-anak hanya akan menjadikan dosa bagi orang tua 


\section{Moh. Waslah}

dan tumbuhnya kebencian yang akan berkembang selamanya pada diri anak dan buah pahitnya akan dipetik dan akan menjadi hidangan bagi orang tua/ walinya sendiri.

Akhir-akhir ini kita saksikan kenistaan orang tua yang melakukan perbuatan yang takkan pernak dilakukan oleh hewan sekasar dan sebuas apapun, termasuk singa. Orang tua yang mencabuli anaknya sendiri, orang tua yang menyiram anaknya yang semestinya ada dalam perlindungannya dengan minyak dan menyulutnya, seorang ayah yang menyiksa anak hingga tewas. Termasuk mereka yang tega mencekik atau membuang bayi merah, yang belum bisa mempertahankan diri. Perbuatan seperti itu bukan saja nista tetapi sekaligus sangat berdosa. Mereka adalah orang yang mengingkari aturan Allah dan kita harus menjauhinya :

Allah berfirman :

Artinya :'Dan Janganlah kamu ikuti orang yang hatinya telah Kami lalaikan, lantaran telah mengingkari (ajaran) Kami serta menuruti hawa nafsunya. Dan adalah keadaan itu melewati batas'. QS. al-Kahfi :28.

Rasulullah SAW pernah bersabda :

Artinya : 'Barang siapa yang terlepas dari syafaat karena melanggar hukum Allah, maka Allah sangat membencinya' HR Abu Daud dari Ibnu Umar

Mengabaikan pendidikan anak, mencampakkan/ ataun tidak mengurusi , menyiksa anak yang tidak berdaya apalagi membunuhnya adalah pelanggaran 
hukum Allah dan Sunnatullah yang secara kodrati menjadi bagian tugas orang tua.

Sebagai negara yang berdasarkan hukum, Indonesia telah berusaha keras untuk memenuhi kewajibannya demi memenuhi hak-hak anak yang merupakan komitmen internasional sebagaimana disepakati dalam dokumen akhir pertemuan United Nations General Assembly for Special Section on Children (UNGASS) ke 27 yang mendeklarasikan " A World Fit for Children" atau Dunia Yang Aman bagi Anak dengan dundangkannya UU No. 23 Tahun 2002 tentang Perlindungan Anak.

Dalam Undang-undang tersebut pengertian anak bahkan dinyatakan dengan sangat mendasar yaitu " anak adalah tunas, potensi dan generasi muda penerus cita-cita perjuangan bangsa, memiliki peran strategis dan mempunyai ciri dan sifat khusus yang menjamin eksistensi bangsa dan negara pada masa depan'.

Dalam pasal 13 ayat (1) dinyatakan bahwa setiap anak selama dalam pengasuhan orang tua, wali atau pihak lain manapun yang bertanggung jawab atas pengasuhan, berhak mendapat perlindungan dari perlakuan : a. diskriminasi, b. eksploitasi, c. penelantaran, d. kekejaman, kekerasan dan penganiayaan, e. kertidak adilan dan f. perlakuan salah lainnya. Pada ayat (2) disebutkan bahwa dalam hal orang tua, wali atau pengasuh anak melakukan segala bentuk perlakuan sebagaimana dimaksud pada ayat (1) maka pelaku dikenakan 


\section{Moh. Waslah}

pemberatan hukuman. Ancaman hukuman tersebut diuraikan lebik lanjut pada Bab XII Pasal 77 s.d. Pasal 90. Dan pemberatan hukuman bagi orang tua yang melakukan perbuatan yang diancamkan adalah ditambah $1 / 3$ dari hukuman yang ditetapkan.

Marilah kita jauhi perbuatan itu dengan melaksanakan tugas sebagai pengayom, pelindung, pendidik yang sabar agar kita terhindar dari murka dan siksa Allah SWT. 


\section{Belajar Dengan Sang Singa}

\section{Daftar Pustaka}

Al-Qur'an dan terjemahnya :1418 H; Mujamma' Al-Malik Fahd li thiba'at al-Mushaf ; Madinah

Bisri, Adib dan Munawir Fattah; 1999; Kamus Al-Bisri ; Pustaka Progressif; Surabaya.

Poerwadarminta, WJS ; 1986 ; Kamus Umum Bahasa Indonesia; Balai Pustaka, Jakarta.

Samples, Bob, 2002; Revolusi Belajar Untuk Anak, Panduan Belajar Sambil Bermain untuk Membuka Pikiran Anak-Anak Anda ;Terjemahan ; Kaifa ; Bandung.

Shadily, Hasan; 1986; Ensiklopedi Indonesia; Edisi Khusus; PT Ichtiar Baru - Van Hoeve Jakarta

Shihab, M. Quraish ;1998; Lentera Hati , Kisah dan Hikmah Kehidupan, Penerbit Mizan, Bandung.

Undang -Undang No. 23 Tahun 2002 Tentang Perlindungan Anak. 
Moh. Waslah

34 | Dinamika Vol. 1, No. 1, Desember 2016 